\title{
Hyperprolactinemia in antipsychotic-naive patients with first-episode psychosis
}

\author{
A. Riecher-Rössler ${ }^{1 *}$, J. K. Rybakowski ${ }^{2}$, M. O. Pflueger ${ }^{1}$, R. Beyrau ${ }^{3}$, R. S. Kahn ${ }^{4}$, P. Malik ${ }^{5}$, \\ W. W. Fleischhacker ; and the EUFEST Study Groupt \\ ${ }^{1}$ University of Basel Psychiatric Clinics, Basel, Switzerland \\ ${ }^{2}$ Department of Adult Psychiatry, Poznan University of Medical Sciences, Poznan, Poland \\ ${ }^{3}$ Department of Clinical Chemistry, University Hospital Basel, Switzerland \\ ${ }^{4}$ Department of Psychiatry, Rudolf Magnus Institute of Neuroscience, University Medical Centre Utrecht, The Netherlands \\ ${ }^{5}$ Department of Biological Psychiatry, Medical University Innsbruck, Austria
}

Background. Hyperprolactinemia is frequent in patients with schizophrenic psychoses. It is usually regarded as an adverse effect of antipsychotics but has recently also been shown in patients without antipsychotic medication. Our objective was to test whether hyperprolactinemia occurs in antipsychotic-naive first-episode patients (FEPs).

Method. In the framework of the European First Episode Schizophrenia Trial (EUFEST), 249 out of 498 FEPs were eligible for this study, of whom 74 were antipsychotic naive. All patients were investigated regarding their serum prolactin levels with immunoassays standardized against the 3rd International Reference Standard 84/500.

Results. Twenty-nine (39\%) of the 74 antipsychotic-naive patients showed hyperprolactinemia not explained by any other reason, $11(50 \%)$ of 22 women and $18(35 \%)$ of 52 men.

Conclusions. Hyperprolactinemia may be present in patients with schizophrenic psychoses independent of antipsychotic medication. It might be stress induced. As enhanced prolactin can increase dopamine release through a feedback mechanism, this could contribute to explaining how stress can trigger the outbreak of psychosis.

Received 9 August 2012; Revised 17 January 2013; Accepted 24 January 2013; First published online 18 April 2013

Key words: Antipsychotic, dopamine, first-episode psychosis, prolactin, schizophrenia, stress.

\section{Introduction}

Hyperprolactinemia is frequently found in patients with schizophrenic psychoses and is usually considered to be an adverse effect of antipsychotic medication. It occurs with most conventional antipsychotics but also during treatment with some new-generation antipsychotics and is mainly associated with $\mathrm{D}_{2}$ receptor affinity (Bushe et al. 2008; Fitzgerald \& Dinan, 2008; Riecher-Rössler et al. 2009). However, there have also been recent reports on hyperprolactinemia in antipsychotic-free patients with first-episode psychosis (Kahn et al. 2008; Aston et al. 2010; Garcia-Rizo et al. 2012) and in patients with an at-risk mental state (ARMS) for psychosis (Aston et al. 2010).

Prolactin is a peptide hormone secreted mainly by prolactin-producing cells of the anterior pituitary.

\footnotetext{
* Address for correspondence: Prof. Dr med. A. Riecher-Rössler, Center for Gender Research and Early Detection, University of Basel Psychiatric Clinics, c/o University Hospital Basel, Petersgraben 4, CH-4031 Basel, Switzerland.

(Email: anita.riecher@upkbs.ch)

† Members of the EUFEST Study Group are listed in the Appendix.
}

Its main function is to induce lactation. The control of prolactin production and secretion is complex (Fig. 1). The main regulatory mechanism is inhibition by dopamine, which is synthesized in neurons of the hypothalamus and then secreted through portal blood into the anterior pituitary, where it exerts its actions on prolactin-producing cells through $\mathrm{D}_{2}$ receptors. Dopamine is thus the main prolactininhibiting factor (PIF) (Fitzgerald \& Dinan, 2008; Low, 2008; Prabhakar \& Davis, 2008). Dopamine tonically inhibits prolactin release. A negative feedback control of prolactin secretion is mediated by a short loop mechanism to the hypothalamus. Prolactin activates prolactin receptors leading to increased dopamine synthesis and release (Fitzgerald \& Dinan, 2008; Low, 2008).

Prolactin secretion is stimulated by sucking but also by stress (Low, 2008; Prabhakar \& Davis, 2008). Prolactin-releasing factors (PRFs) probably include thyrotropin-releasing hormone (TRH), vasoactive intestinal polypeptide (VIP) and oxytocin. Estrogens also stimulate prolactin synthesis through a positive feedback loop, and indirectly through their antidopaminergic properties (Low, 2008). 


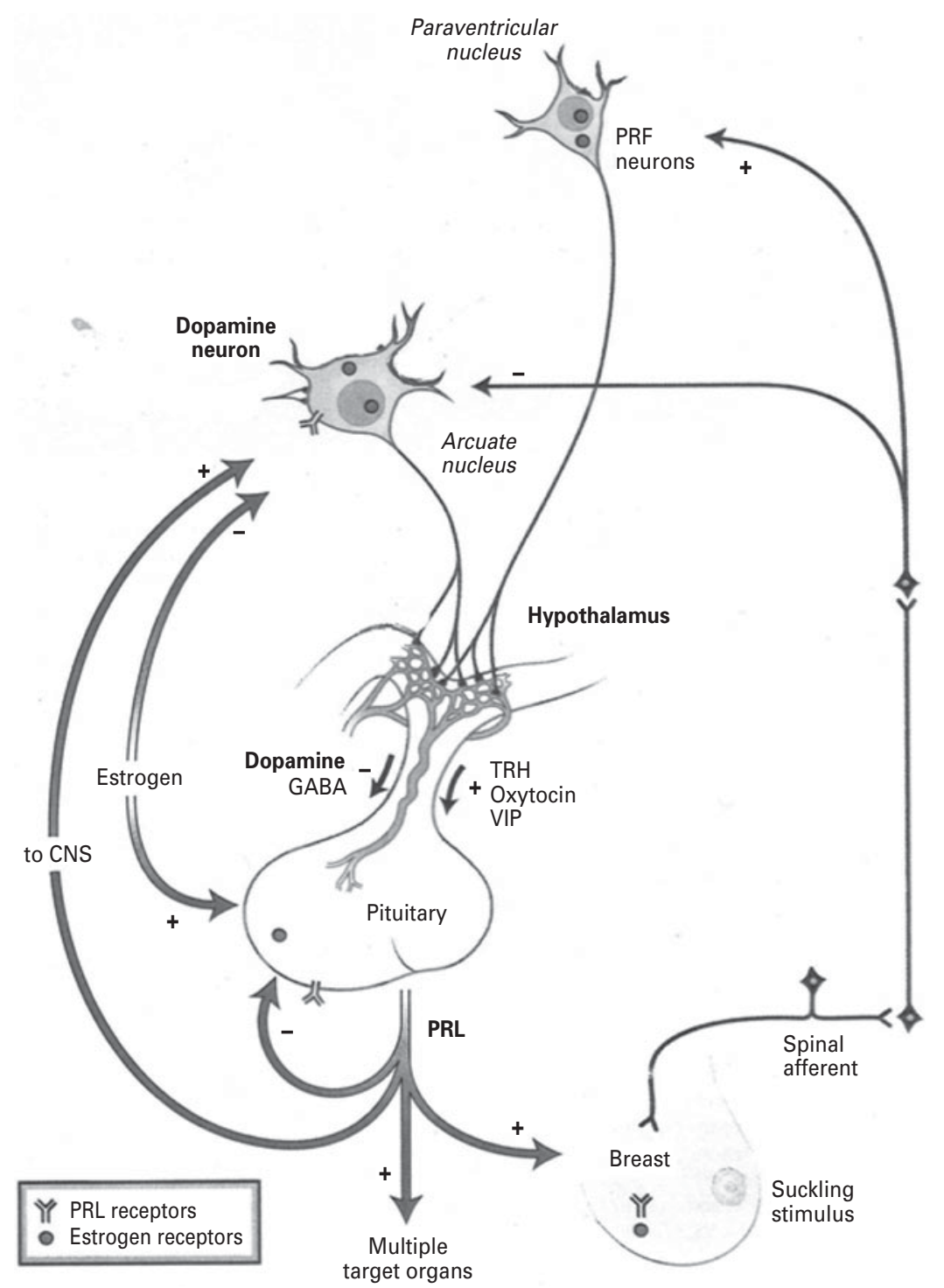

Fig. 1. Control of prolactin (PRL) production and secretion. PRF, prolactin-releasing factor; TRH, thyrotropin-releasing hormone; VIP, vasoactive intestinal polypeptide; GABA, $\gamma$-aminobutyric acid; CNS, central nervous system. Reproduced, with permission from Elsevier, from W. J. Low (2008). Neuroendocrinology. In Williams Textbook of Endocrinology (ed. H. M. Kronenberg, S. Melmed, K. S. Polonsky and P. R. Larsen), 9th edn, pp. 85-295. W.B. Saunders Co.: Philadelphia, PA.

Hyperprolactinemia (i.e. prolactin serum values above the normal range) can be caused by many physiological processes, by psychological distress (for review see Low, 2008; Prabhakar \& Davis, 2008), and also by pathological conditions such as prolactinsecreting tumors. Thus, hyperprolactinemia in patients with schizophrenic psychoses may not only be treatment related but also possibly disease related.

Hyperprolactinemia can suppress gonadal function with a reduced physiological production of estrogens and testosterone (Dickson et al. 2000; Prabhakar \& Davis, 2008). This can have serious clinical consequences (e.g. sexual dysfunction, infertility or osteopenia) in both men and women (for review see (Haddad \& Wieck, 2004; Miller, 2004; Prabhakar \& Davis, 2008; Riecher-Rössler et al. 2009).

We therefore aimed to determine, in the framework of the European First Episode Schizophrenia Trial (EUFEST; Fleischhacker et al. 2005; Kahn et al. 2008), whether antipsychotic-naive first-episode patients (FEPs) show hyperprolactinemia and, if so, whether it is associated with factors such as pretreatment, age, gender or severity of illness. To our knowledge this is one of the largest samples of antipsychotic-naive first-episode psychosis patients studied regarding these issues. 


\section{Method}

Data were obtained as part of the EUFEST, the methodology of which has been described in more detail in previous publications (Fleischhacker et al. 2005; Kahn et al. 2008). A total of 50 centers participated. Eligible patients were aged 18-40 years and met DSM-IV criteria for schizophrenia, schizophreniform disorder or schizo-affective disorder. Onset of positive symptoms had to have occurred no more than 2 years before study entry, and no more than 6 weeks of lifetime exposure to antipsychotics was allowed. After complete description of the study to the subjects, written informed consent was obtained. The trial complied with the Declaration of Helsinki, and was approved by the ethics committees of the participating centers. The Julius Center for Health Sciences and Primary Care monitored the trial according to Good Clinical Practice and International Conference on Harmonisation guidelines.

We included 249 patients from the EUFEST sample (total 498 patients) in the current study. The remaining 249 patients were excluded for the following reasons: in 222 it could not be safely confirmed that they had had their blood samples for prolactin drawn before having received their first antipsychotic medication, 21 had unknown previous medications apart from antipsychotics, and six were non-Caucasian. The latter were excluded as there is some evidence that there might be ethnic differences regarding the hormonal response to psychological stressors (Chong et al. 2008).

Baseline data included demographics, diagnosis, treatment setting, psychopathology [Positive and Negative Syndrome Scale (PANSS); Kay et al. 1987], severity of illness [Clinical Global Impressions (CGI) scale; Guy, 1976], and other parameters described in the original papers. Pretreatment history was ascertained by questioning patients and significant others, in addition to reviewing available charts.

\section{Prolactin measurements}

In each center, immunoassays were used for prolactin measurements, which were standardized against the 3rd International Reference Standard 84/500. The lower and upper reference limits were calculated as the 5th and 95th percentiles. Hyperprolactinemia in this reference is defined as a value above the 95th percentile, that is $>0.38 \mathrm{U} / 1$ in men and $>0.53 \mathrm{U} / 1$ in women. To convert values from $\mathrm{ng} / \mathrm{ml}$ to $\mathrm{U} / \mathrm{l}$ we used a conversion factor of 0.0212 (Kahn et al. 2008).

\section{Statistical methods}

The $\mathrm{R}$ environment for statistical computation was used to analyze the EUFEST dataset ( $R$ Development
Core Team, 2011). Simple parametric and nonparametric statistical tests, such as the Mann-Whitney $U$ test and the Student $t$ test, were performed to analyze group differences. $\chi^{2}$ tests and Fisher's exact tests were applied wherever count data were analyzed.

Log-transformed prolactin values were modeled by age, sex and PANSS positive/negative score to account for the influence of relevant variables. A generalized linear model (GLM) approach was adopted, specified by a log link function and gamma family distribution. As the mean function indicates a squared relationship between mean log prolactin and its standard deviation, the assumption of an exponential residual distribution seems to be justified and hence the choice of a GLM belonging to the gamma family. An analysis of deviance was performed to determine a particular factor's contribution in explaining prolactin deviance [a concept functional equivalent to variance in ordinary least squares analysis but specific to GLMs and other modern approaches in linear modeling].

\section{Results}

Of the 249 FEP patients with reliable records on medication before prolactin measurements, 74 (52 men and 22 women) were naive for the intake of any antipsychotic medication. Clinical and demographic characteristics of the 74 antipsychotic-naive and the 175 not-naive patients are summarized in Table 1.

\section{Hyperprolactinemia in antipsychotic-naive patients}

As expected, a high proportion of the patients with prior or current intake of antipsychotics showed hyperprolactinemia (i.e. levels above the upper limit of the normal range). However, 30 (40.5\%) of the 74 antipsychotic-naive patients also showed hyperprolactinemia: 11 (50\%) of the 22 women and 19 (36.5\%) of the 52 men.

The mean prolactin values were also strongly elevated not only in the non-naive but also in the antipsychotic-naive patients, and the elevation was especially high in women. Table 2 shows the proportion of patients with hyperprolactinemia in both groups according to gender, along with the mean prolactin values.

For further analyses, unless stated otherwise, we focused on the antipsychotic-naive sample.

\section{Influence of other previous medications}

Of the 30 antipsychotic-naive patients with hyperprolactinemia, 20 had taken some other medication: benzodiazepines $(n=13)$, biperiden $(n=3)$, pridinol 
Table 1. Sociodemographic and clinical characteristics of antipsychotic-naive versus non-naive first-episode patients (FEPs)

\begin{tabular}{|c|c|c|c|c|}
\hline & $\begin{array}{l}\text { Antipsychotic naive } \\
(n=74)\end{array}$ & $\begin{array}{l}\text { Antipsychotic non-naive } \\
(n=175)\end{array}$ & $\begin{array}{l}\text { Total } \\
(n=249)\end{array}$ & $p$ \\
\hline Men/women, $n(\%)$ & $52(70) / 22(30)$ & $105(60) / 70(40)$ & $157(63) / 92(37)$ & $0.151^{\mathrm{a}}$ \\
\hline Age (years), mean \pm s.D. & $25.8 \pm 2.8$ & $26.0 \pm 5.5$ & $25.9 \pm 5.5$ & $0.739^{\mathrm{b}}$ \\
\hline Years of education, mean \pm S.D. & $12.8 \pm 2.8$ & $12.6 \pm 3.1$ & $12.7 \pm 3.0$ & $0.376^{\mathrm{b}}$ \\
\hline \multicolumn{5}{|l|}{ Diagnosis, $n$} \\
\hline Schizophrenic psychosis & 46 & 84 & 30 & \\
\hline Schizo-affective psychosis & 6 & 15 & 21 & $0.106^{\mathrm{c}}$ \\
\hline Schizophreniform disorders & 22 & 76 & 98 & \\
\hline
\end{tabular}

S.D., Standard deviation.

${ }^{\text {a }}$ Fisher's exact test for count data.

${ }^{\mathrm{b}}$ Mann-Whitney $U$ test for ranked data.

${ }^{c} \chi^{2}$ test for contingency tables.

Table 2. Hyperprolactinemia and prolactin values of antipsychotic-naive versus non-naive patients with first-episode psychosis

\begin{tabular}{|c|c|c|c|c|c|c|}
\hline & \multicolumn{3}{|c|}{ Antipsychotic naive } & \multicolumn{3}{|c|}{ Antipsychotic non-naive } \\
\hline & $\begin{array}{l}\text { Men } \\
(n=52)\end{array}$ & $\begin{array}{l}\text { Women } \\
(n=22)\end{array}$ & $\begin{array}{l}\text { Total } \\
(n=74)\end{array}$ & $\begin{array}{l}\text { Men } \\
(n=105)\end{array}$ & $\begin{array}{l}\text { Women } \\
(n=70)\end{array}$ & $\begin{array}{l}\text { Total } \\
(n=175)\end{array}$ \\
\hline $\begin{array}{l}\text { Proportion of patients with } \\
\text { hyperprolactinemia }{ }^{\mathrm{a}}, n(\%)\end{array}$ & $19(36.5)$ & $11(50.0)$ & $30(40.5)$ & $75(71.4)$ & $52(74.3)$ & $127(72.6)$ \\
\hline \multicolumn{7}{|l|}{ Prolactin (U/l) blood levels } \\
\hline Mean \pm S.D. & $0.37 \pm 0.32$ & $0.98 \pm 0.94$ & $0.55 \pm 0.64$ & $0.83 \pm 0.91$ & $1.60 \pm 1.44$ & $1.14 \pm 1.21$ \\
\hline Median & 0.26 & 0.58 & 0.34 & 0.68 & 1.16 & 0.80 \\
\hline Range & $0.04-1.50$ & $0.11-3.29$ & $0.04-3.29$ & $0.00-8.58$ & $0.10-6.66$ & $0.00-8.58$ \\
\hline \multicolumn{7}{|l|}{ Men versus women } \\
\hline Mann-Whitney $U$ test & 850.5 & & & 4956.0 & & \\
\hline$p$ value & $<0.001$ & & & $<0.001$ & & \\
\hline
\end{tabular}

S.D., Standard deviation.

${ }^{a}$ Normal values: men $<0.38 \mathrm{U} / 1$; women $<0.53 \mathrm{U} / 1$.

$(n=2)$, hydroxyzine $(n=1)$, propanolol $(n=1)$, metoclopramide $(n=1)$, cetirizine $(n=1)$, omeprazol $(n=1)$ and sulfacetamide $(n=1)$. None of the antipsychoticnaive women had taken oral contraceptives. There was no significant difference in prolactin values between the 20 patients with previous medication (mean $1.22 \pm 0.86 \mathrm{U} / \mathrm{l}$ ) and the 10 who were completely medication naive (mean $0.70 \pm 0.30 \mathrm{U} / \mathrm{l}$, Mann-Whitney $U=64, p=0.118$ ). Only one of these patients had taken drugs known to increase prolactin (metoclopramide and omeprazol). For further analyses we excluded this patient. We were thus left with 29 out of 74 (39.2\%) FEP patients whose hyperprolactinemia could not be explained by antipsychotics or any other medication.

\section{Influence of age and gender}

There was no significant age difference between the 29 antipsychotic-naive patients with unexplained hyperprolactinemia (mean age $25.1 \pm 5.4$ years) and the 44 antipsychotic-naive with normal prolactin values (mean age 26.2 \pm 5.7 years) $(t=0.8, \mathrm{df}=72, p=0.412)$, but there were significant gender differences. Antipsychotic-naive women had higher prolactin values than men, and the range of values was much larger in the female patients (Fig. 2).

\section{Influence of symptomatology}

We also tested whether hyperprolactinemia was associated with the severity of psychopathological 


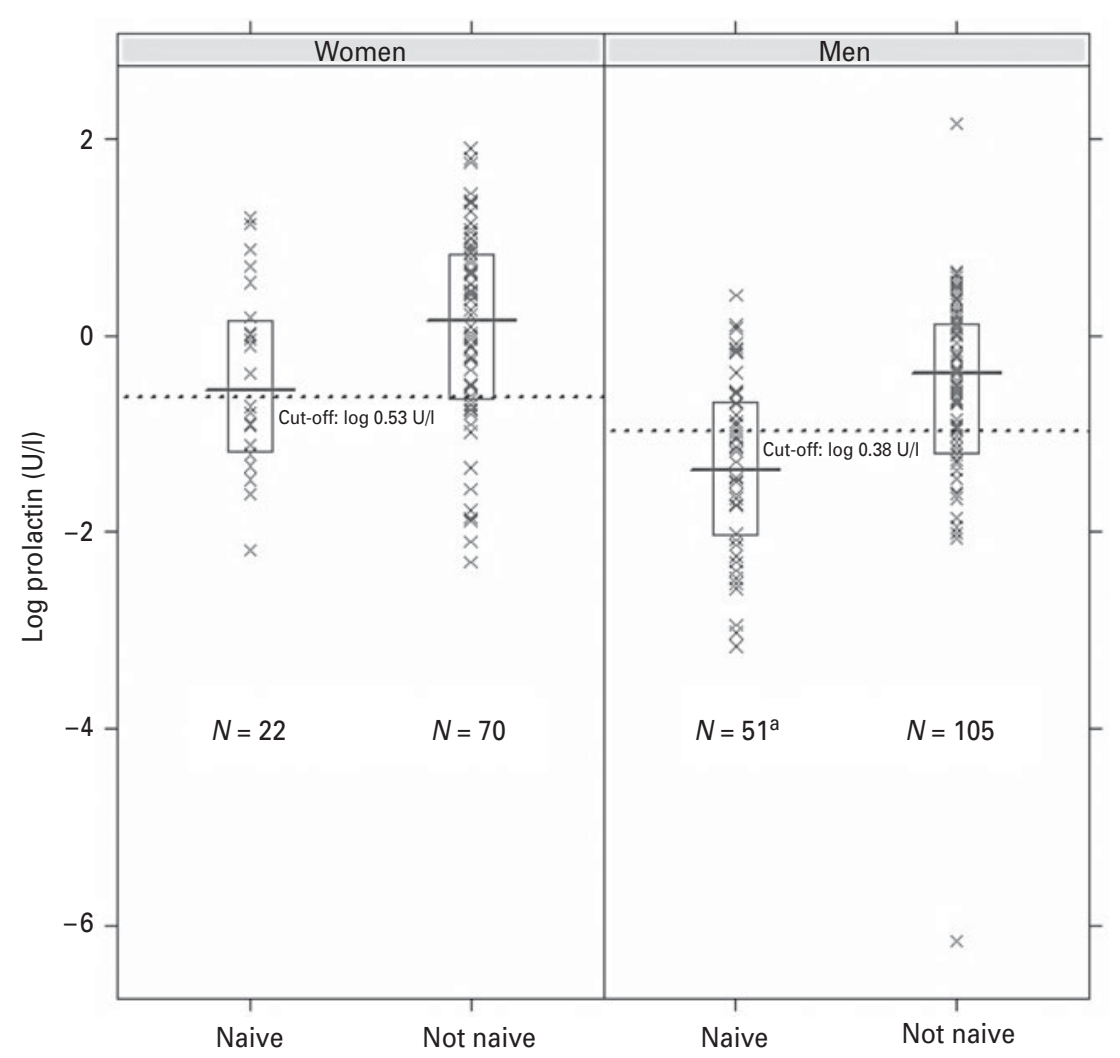

Fig. 2. Prolactin values of patients with first-episode psychosis, naive and not naive for antipsychotics, differentiated by gender. Log prolactin levels depend on gender and neuroleptic treatment. Dotted lines indicate a gender-specific cut-off value. Values above this line represent hyperprolactinemia. The boxes surrounding some of the values comprise all values that fall within the first and third quantiles. The horizontal line that is approximately centered within the box corresponds to the median of the particular subsample. ${ }^{\text {a }}$ After exclusion of one man (see text).

symptoms and/or diagnostic subtype in antipsychoticnaive patients. Table 3 shows the different PANSS and CGI scores and also specific diagnoses for all antipsychotic-naive patients, comparing the groups with and without unexplained hyperprolactinemia. There was no diagnostic subtype disproportionately more frequently affected by hyperprolactinemia. Patients with hyperprolactinemia did not differ from patients without hyperprolactinemia in terms of the severity of psychopathological symptoms. Furthermore, there was no correlation of $\log$ prolactin values with the total CGI score (Spearman's $\rho=0.02$, $p=0.850)$, the PANSS positive score $\left(r=0.04, t_{72}=0.31\right.$, $p=0.756)$ or the PANSS negative score $\left(r=0.11, t_{72}=\right.$ $0.95, p=0.345)$. Additionally, we tested the correlation with the anxio-depressive dimension of the PANSS according to El Yazaji et al. (2002), and this was also not significant $\left(r=0.04, t_{72}=0.30, p=0.763\right)$.

\section{GLM}

In a next step we analyzed the factors potentially influencing prolactin levels, such as sex, age and severity of psychopathology, that is PANSS positive and negative scores, within the 73 antipsychotic-naive patients. Using an analysis of deviance of a GLM, we entered age, gender and the PANSS positive and negative scores into the model.

Age and the PANSS positive score did not contribute to explaining a significant amount of variance of the data. However, there were significant main effects of gender $\left(\chi^{2}=24.9, \mathrm{df}=1, p<0.001\right)$ and the PANSS negative score $\left(\chi^{2}=4.6, \mathrm{df}=1, p=0.032\right)$, and an interaction of gender with the PANSS negative score $\left(\chi^{2}=7.9, \mathrm{df}=1, p=0.005\right)$. The mean prolactin level in women with an average negative symptom load (PANSS negative) amounted to $0.98 \mathrm{U} / 1$. By contrast, the mean prolactin level in men was only $37 \%$ of the value seen in women. The negative symptoms (PANSS negative) yielded a differential effect on the prolactin level depending on gender: whereas an increasing value of the PANSS negative score was strongly associated with a decreased prolactin level in women ( $-7 \% /$ scale unit PANSS negative), a slightly inverse relationship was found in men $(+3 \% /$ unit PANSS negative). 
Table 3. Psychopathological symptoms of antipsychotic-naive first-episode patients (FEPs) with and without unexplained hyperprolactinemia $(H P)$

\begin{tabular}{|c|c|c|c|c|}
\hline & No HP $(n=44)$ & Unexplained HP $(n=29)^{\mathrm{a}}$ & Total $(n=73)^{\mathrm{a}}$ & Statistics \\
\hline Men/women, $n(\%)$ & $33(65) / 11(50)$ & $18(35) / 11(50)$ & $51(100) / 22(100)$ & $p=0.300$ \\
\hline Age (years), mean (s.D.) & $26.2(5.7)$ & $25.3(5.3)$ & $25.8(5.6)$ & $t_{71}=0.66, p=0.512^{\mathrm{b}}$ \\
\hline \multicolumn{5}{|l|}{ PANSS, mean (S.D.) } \\
\hline Positive score & $20.9(6.2)$ & $21.0(5.7)$ & $20.9(6.2)$ & $t_{71}=0.08, p=0.931^{\mathrm{b}}$ \\
\hline Negative score & $18.6(8.2)$ & $21.2(7.1)$ & $21.3(6.0)$ & $t_{71}=1.40, p=0.167^{\mathrm{b}}$ \\
\hline Anxio-depressive dimension $^{c}$ & $9.8(3.4)$ & $9.8(3.8)$ & $9.8(3.5)$ & $t_{71}=0.09, p=0.931^{\mathrm{b}}$ \\
\hline \multicolumn{5}{|l|}{ CGI, $n(\%)$} \\
\hline Borderline mentally ill & $2(5)$ & $0(0)$ & $2(3)$ & $p=0.514^{\mathrm{d}}$ \\
\hline Mildly ill & $1(2)$ & $2(7)$ & $3(4)$ & $p=0.559^{\mathrm{d}}$ \\
\hline Moderately ill & $13(30)$ & $8(28)$ & $21(28)$ & $p \approx 1.00^{\mathrm{d}}$ \\
\hline Markedly ill & $23(52)$ & $14(48)$ & $38(51)$ & $p=0.813^{\mathrm{d}}$ \\
\hline Severely ill & $5(11)$ & $5(17)$ & $10(14)$ & $p=0.505^{\mathrm{d}}$ \\
\hline \multicolumn{5}{|l|}{ Diagnostic subtype, $n(\%)$} \\
\hline Paranoid & $22(50)$ & $17(59)$ & $39(53)^{\mathrm{e}}$ & $p=0.485^{\mathrm{d}}$ \\
\hline Schizophreniform & $15(34)$ & $7(24)$ & $22(30)^{\mathrm{e}}$ & $p=0.440^{\mathrm{d}}$ \\
\hline Schizo-affective & $3(7)$ & $3(10)$ & $6(8)^{\mathrm{e}}$ & $p=0.676^{\mathrm{d}}$ \\
\hline Undifferentiated & $4(9)$ & $2(7)$ & $6(8)^{e}$ & $p \approx 1.00^{\mathrm{d}}$ \\
\hline
\end{tabular}

PANSS, Positive and Negative Symptom Scale; CGI, Clinical Global Impression; S.D., standard deviation.

${ }^{a}$ One patient with intake of prolactin-increasing medication (metoclopramide and omeprazol) was excluded.

${ }^{\mathrm{b}}$ Two-sample Student's $t$ test.

${ }^{c}$ PANSS items G1, G2, G3, G6.

${ }^{\mathrm{d}}$ Fisher's exact test for count data.

e Percentages do not add up to $100 \%$ due to rounding errors.

\section{Clinical sequelae}

With regard to potential clinical sequelae of hyperprolactinemia, patients were specifically asked about galactorrhea or amenorrhea. None of the antipsychotic-naive patients suffered from galactorrhea and only two of the women had amenorrhea, both in the group with hyperprolactinemia.

\section{Discussion}

We have studied 74 antipsychotic-naive FEPs with psychosis within the EUFEST study (Fleischhacker et al. 2005; Kahn et al. 2008). Twenty-nine (39.2\%) of these FEPs showed hyperprolactinemia unexplained by any medication or other known influence. To our knowledge this is one of the largest samples of antipsychotic-naive FEP patients studied regarding this issue. Our findings indicate that hyperprolactinemia in FEP is not necessarily only caused by antipsychotics, but might also be a pre-existing condition in some patients. This corroborates a previous finding from the Basel early-detection-of-psychosis (FEPSY) study (Aston et al. 2010), in which hyperprolactinemia was found in $33 \%$ of all antipsychotic-naive
FEP patients, and even in $24 \%$ of antipsychotic-naive patients with an ARMS for psychosis. Similarly, Garcia-Rizo et al. (2012) have recently reported higher prolactin concentrations in 33 newly diagnosed antipsychotic-naive patients with non-affective psychosis compared to 33 matched controls in a wellcontrolled study. Guest et al. (2011) have also reported elevated prolactin concentrations in the blood of 236 first-episode and recent-onset patients with schizophrenic psychoses compared to 230 matched controls. Patients were antipsychotic naive or antipsychotic free for at least 6 weeks. Segal et al. (2004) only found higher prolactin levels in the disorganized subtype of schizophrenic psychoses. Their sample consisted of first-episode and recurrent patients, both unmedicated. Meltzer et al. (21) and Kuruvilla et al. (22) were not able to demonstrate differences in mean prolactin values between smaller samples of newly admitted unmedicated schizophrenic psychoses patients and healthy controls. However, the prevalence of hyperprolactinemia (i.e. the proportion of patients with levels above the norm) was not reported in their studies and mean values might not be as informative.

It has previously been suggested that hyperprolactinemia may have been present before the introduction 
of antipsychotics in some patients with schizophrenic psychoses (Riecher-Rössler \& Häfner, 1993; RiecherRössler et al. 1998). Indirect evidence for this stems from earlier observations of gonadal dysfunction and hypoestrogenemia in unmedicated patients with schizophrenic psychoses. Both suppression of gonadal function and suppression of estrogen production are well known consequences of hyperprolactinemia and both have been described as early as at the beginning of the last century, when antipsychotics had not yet been developed (for review see Riecher-Rössler \& Häfner, 1993; Riecher-Rössler et al. 1998). Thus, Kraepelin (1909-1915) and Kretschmer (1921) had already reported that many women with schizophrenic psychoses showed physical signs indicating 'insufficient functioning of the sexual glands' with 'hypoestrogenism'. In the 1930s, studies analyzing estrogen levels in blood and urine found decreased estrogen levels in most in-patients with schizophrenic psychoses (Riecher-Rössler \& Häfner, 1993; Riecher-Rössler et al. 1998). Again, antipsychotics were not available then. Prolactin levels were not measured in those days.

Our findings are also in line with recent MRI findings that showed an increased pituitary volume in antipsychotic-free FEP patients and even in patients with an ARMS for psychosis, especially in those with a later transition to frank psychosis (Garner et al. 2005; Pariante, 2008; Büschlen et al. 2010; Walter et al. 2012), although there is a recent study at odds with this (Klomp et al. 2012). As prolactin production in the pituitary is known to be associated with an enlargement of the gland (MacMaster et al. 2007), this could theoretically indicate increased prolactin production during emerging psychosis.

\section{Potential clinical implications}

Our findings, if confirmed, would have implications for research and also for clinical practice. Hyperprolactinemia can have many adverse clinical effects (Riecher-Rössler et al. 2009). Not only can it lead to galactorrhea, but it can also suppress the activity of the hypothalamic-pituitary-gonadal (HPG) axis and gonadal function, leading to a reduced physiological production of estrogens and testosterone (Dickson et al. 2000; Prabhakar \& Davis, 2008). It may cause amenorrhea and menstrual irregularities in women and erectile dysfunction, along with ejaculatory problems and reduced spermatogenesis, in men. In both genders it can be associated with emotional lability, loss of libido, orgasmic dysfunction and infertility (Haddad \& Wieck, 2004; Miller, 2004; Prabhakar \& Davis, 2008; Riecher-Rössler et al. 2009). As was shown in the total sample of all FEPs of the EUFEST study, higher prolactin plasma levels predict amenorrhea in women and erectile and ejaculatory dysfunction in men (Malik et al. 2011). Chronic hyperprolactinemia has also been associated with osteopenia and osteoporosis (O'Keane \& Meaney, 2005) and an increase in the risk of bone fracture (Howard et al. 2007), although exposure to prolactin-increasing antipsychotics in one study was not found to be related to bone mineral density (Hummer et al. 2005). Finally, there has been some discussion about a possible relationship between hyperprolactinemia and a slightly increased risk for breast cancer (Prabhakar \& Davis, 2008; Bushe et al. 2009).

Most of the mentioned sequelae of hyperprolactinemia are indirect effects caused by the suppression of gonadal estrogen and testosterone production. Only a few, such as galactorrhea, are direct effects of hyperprolactinemia (Riecher-Rössler et al. 2009). The potentially increased risk of breast cancer is also thought to be such a direct effect. These direct effects have mainly been documented in patients with other causes of high prolactin levels, such as prolactinoma, which lead to considerably higher levels of plasma prolactin than those reported here.

From an endocrinological point of view, prolactin levels should be measured before commencing antipsychotic treatment to ensure that hyperprolactinemia is not a pre-existing condition, which would need thorough investigation. Blood samples should be taken in a standardized manner (in the morning between 08:00 and 10:00 h, without any stressful influences, etc.). If hyperprolactinemia is found and deemed not to be drug related, other causes such as thyroid hypofunction or tumors in the area of the pituitary need to be excluded. Potential adverse clinical sequelae should be treated if hyperprolactinemia is persisting and cannot be treated causally.

\section{Potential research implications}

Besides potential clinical consequences, our findings may also have implications for research. It might be that, in antipsychotic-naive patients with prodromal states or first-episode psychosis, hyperprolactinemia is caused by psychological distress associated with the (emerging) illness. It is well known that stress can activate not only cortisol but also prolactin secretion (Low, 2008; Prabhakar \& Davis, 2008). The increased pituitary volumes seen in these patients might be due not only to an increase in the production of adrenocorticotropic hormone (ACTH), as suggested previously (Pariante, 2008), but also to an increase in the production of prolactin in the pituitary (MacMaster et al. 2007).

Furthermore, it might be speculated that stressinduced hyperprolactinemia plays a role in triggering the outbreak of acute psychotic symptomatology 
because hyperprolactinemia induces the production of prolactin-inhibiting factor (PIF), which is more or less identical with dopamine (Low, 2008).

Dopaminergic transmission is well known to be increased in acutely psychotic patients and even in people at risk for psychosis (Howes \& Kapur, 2009). Furthermore, stress in such individuals has been linked to both an increase of symptoms and an increase in dopaminergic indices (van Winkel et al. 2008; Howes \& Kapur, 2009; van Os et al. 2010; Mizrahi et al. 2012). It is accepted that different forms of stress can enhance the risk for psychosis and may trigger its outbreak acutely (Phillips et al. 2006; van Winkel et al. 2008; Howes \& Kapur, 2009; van Os et al. 2010). This has been integrated into an 'advanced' dopamine hypothesis as the final common pathway for psychosis (Howes \& Kapur, 2009). However, the exact mechanisms of how stress influences dopaminergic neurotransmission are not yet completely understood (Phillips et al. 2006; van Winkel et al. 2008; Howes \& Kapur, 2009; Ungless et al. 2010; van Os et al. 2010).

Ungless et al. (2010), in a review of the effects of stress on dopamine neurons, state that 'a major target of stress, and stress-related hormones in particular, are fast excitatory and inhibitory synapses made onto dopamine neurons'. This is where prolactin, which also serves as a stress hormone, may play a possible role in the pathogenesis of (emerging) psychosis as it can directly enhance dopamine levels through a feedback mechanism (Fitzgerald \& Dinan, 2008; Low, 2008) (see Fig. 1). Stress can, among other factors, induce hyperprolactinemia, which in turn, as a regulatory mechanism to down-regulate prolactin secretion, induces an increase in PIF (i.e. dopamine). This increase in dopamine would then be able to trigger psychotic symptoms in individuals vulnerable for psychosis. This would mean that the tuberoinfundibular dopamine pathway may be involved in the pathogenesis of schizophrenic psychoses, and not just the mesolimbic and mesocortical pathways as hypothesized prominently in the literature.

This extension of the stress-dopamine hypothesis could help to explain the well-known fact that stress can trigger the outbreak of psychotic symptoms. It might also help to explain why many patients develop schizophrenic psychoses during periods of their lives with strong fluctuations of sex hormones and prolactin, such as during adolescence or, in women, during the postpartum or perimenopausal period (Häfner et al. 1993; Riecher-Rössler \& Häfner, 1993; RiecherRössler et al. 1994, 1998).

Of note, hyperprolactinemia and also the increase in the pituitary volume found in our and other studies (Büschlen et al. 2010) have been demonstrated predominantly in women. At the same time, it has been shown that women have a stronger prolactin response to antipsychotics (Yasui-Furukori et al. 2010). Both findings might be explained by the fact that estrogens sensitize the pituitary to release prolactin (Fitzgerald \& Dinan, 2008; Low, 2008). In this context it is also of interest that men and women react differently to stress (Kirschbaum et al. 1999).

We could not confirm our hypothesis that prolactin levels are associated with the severity of positive psychotic symptomatology. However, we did find a gender difference regarding negative symptoms. More negative symptoms were related to lower prolactin levels in antipsychotic-naive women but to higher levels in antipsychotic-naive men. These gender differences are difficult to explain. It is possible that the intense stress reaction in women with a very high rise of prolactin is attenuated by negative symptoms such as affective flattening.

However, our contrasting finding in men is in accordance with that of Akhondzadeh et al. (2006), who found a positive correlation between prolactin plasma levels and negative subscale scores in male patients with chronic schizophrenia. At the same time, their patients had low testosterone levels, which might indicate that hyperprolactinemia-induced suppression of gonadal function with a decrease in testosterone production can result in an increase of negative symptoms. This might open up new therapeutic options with adjunctive testosterone in negative symptoms (Akhondzadeh et al. 2006), similar to the adjunctive treatment with estrogens for positive symptoms (for review see Riecher-Rössler \& de Geyter, 2007; Riecher-Rössler \& Kulkarni, 2011).

There are also genetic links between prolactin and schizophrenic psychoses. The prolactin gene has been mapped to chromosome 6p21 (Evans et al. 1989) and this region has long been discussed as a susceptibility locus for schizophrenic psychoses genes (Schwab et al. 2003; Tochigi et al. 2004; Roig et al. 2007). Stevens et al. (2001) identified a functional polymorphism -1149 G/T (rs1341239) of the prolactin gene, where the $G$ allele has been associated with higher promoter activity of the gene and a greater increment of prolactin mRNA. In a first study of this polymorphism, a significant preponderance of this allele was found in patients with schizophrenic psychoses compared to healthy controls (Rybakowski et al. 2011). It could therefore be hypothesized that individuals with a preponderance of the $\mathrm{G}$ allele react more strongly to stress and thus show a higher risk of psychotic breakdown.

\section{Limitations}

We cannot completely rule out the possibility that some patients who claimed never to have received an 
antipsychotic may have nevertheless been pretreated. We consider this possibility unlikely given the early stage of the illness and the fact that we had good back-up information from relatives and patient records. Very extensive questioning about previous medication was a focus of the EUFEST study, so we can assume that under-reporting was very low. If there was any doubt, patients were excluded from the prolactin study. In addition, even if we made erroneous assumptions about some patients' pretreatment status, it would be difficult to explain our finding of a considerable increase in prolactin across the full sample.

Because prolactin levels were not measured in a central laboratory but rather in the individual study centers, there may have been some variation in absolute prolactin level differences. However, as all centers used immunoassays standardized against the 3rd International Reference Standard 84/500, the assessment of 'hyperprolactinemia' seems correct.

Prolactin secretion follows a circadian and ultradian rhythm and to a lesser extent depends on the phase of the menstrual cycle. Although centers were instructed to collect blood samples in the morning, there was no control for menstrual cycle-dependent variations in female patients, which may have contributed to variance in prolactin levels in females. However, apart from the magnitude of effects, we did find increased prolactin levels in both sexes.

Lastly, given our rigorous exclusion approach, we were left with a relatively small patient sample of truly antipsychotic-naive individuals. At the same time, however, this rigorous approach is a strength of our study.

\section{Conclusions}

Clinically, our findings indicate that prolactin should be measured in patients with first-episode psychosis and putative prodromal states before the introduction of antipsychotics. In terms of research, our findings may contribute to explaining how stress may trigger the outbreak of schizophrenic psychoses: stress induces hyperprolactinemia that, through feedback, can increase dopamine. The latter is certainly speculative but should stimulate further research.

\section{Appendix. EUFEST Study Group}

Principal Investigators: R. S. Kahn, W. W. Fleischhacker. Executive Committee: R. S. Kahn, I. P. M. Keet (trial coordinator until July 2004), H. Boter (trial coordinator since July 2004). Management Group: R. S. Kahn, W. W. Fleischhacker, H. Boter, C. Brugman,
H. Burger, D. E. Grobbee, M. C. Hafkamp, I. P. M. Keet, K. Nijssen. Steering Committee: R. S. Kahn, W. W. Fleischhacker, H. Boter, I. P. M. Keet, C. Brugman, M. Davidson, S. Dollfus, W. Gaebel, S. Galderisi, M. Gheorghe, I. Gonen, D. E. Grobbee, L. G. Hranov, M. Hummer, J. Libiger, N. Lindefors, J. J. López-Ibor, K. Nijssen, J. Peuskens, A. Riecher-Rössler, J. K. Rybakowski, G. Sedvall, M. v. Wilmsdorff. Office Manager: P. C. Ywema. Julius Centre Study Team: data management: N. Boekema, H. den Breeijen, M. van den Haak, P. Huizinga, R. Veen; project managers: C. Brugman, M. C. Hafkamp, K. M. Nijssen; site monitoring: P. Berackova, A. Blizanowska, C. Brugman, M. C. Hafkamp, T. Huizinga, H. van Gelderen, M. Gordat, S. Lorteau, G. Makhanlal, H. Moqadar. Tangent Data Study Team (co-monitoring Romania): I. Gonen, A. Mihailescu, R. Radici, C. Zus. Participating investigators $(\mathrm{CC}=$ country coordinator; $\mathrm{SC}=$ site coordinator), centers, and countries: Austria: M. Hummer (CC and SC Innsbruck), M. Muhlbacher (SC Salzburg), H. Widmoser (SC Hall in Tirol); Belgium: J. Peuskens (CC), J. Hulselmans (SC Antwerpen), C. Mertens (SC Gent), E. Thijs (SC Kortenberg); Bulgaria: L. G. Hranov (CC and SC Sofia), S. Georgiev (SC Plovdiv), L. Sayan (SC Bourgas); Czech Republic: J. Libiger (CC and SC Hradec Králové), E. Češková (SC Brno), D. Seifertová (SC Praha-Bohnice); France: S. Dollfus (CC and SC Caen I), G. Allio (SC Rouen), B. Chabot (SC Caen II), A. N. Coulaud (SC Dieppe), P. Thomas (SC Lille); Germany: W. Gaebel (CC), M. Krebs (SC Berlin), R. Lencer (SC Lübeck), K. Leopold (SC Berlin), T. Wobrock (SC Homburg); Israel: M. Davidson (CC), Y. Abramovitch (SC Beer-Yaakov), D. Amital (SC Ness Ziona), A. Caspi (SC Ramat Gan), A. Kaplan (SC Beer Sheva), I. Treves (SC Shalvata), P. Zipris (SC Pardessiya); Italy: S. Galderisi (CC), M. Casacchia (SC L'Aquila), G. Invernizzi (SC Milano II), A. Mucci (SC Naples), S. Scarone (SC Milano I), A. Vita (SC Melzo); The Netherlands: H. Boter (CC and SC Utrecht), I. P. M. Keet (CC and SC Utrecht); Poland: J. K. Rybakowski (CC and SC Poznan), M. Jarema (SC Warsaw), M. Masiak (SC Lublin), J. Rabe-Jablonska (SC Lodz); Romania: M. Gheorghe (CC), V. Burtea (SC Brasov), P. Boisteanu (SC Iasi), C. Friedman (SC Constanta), M. Ienciu (SC Timisoara), A. Ionescu (SC Buzau), I. Miclutia (SC Cluj), T. Mihai (SC Tulcea), D. Prelipceanu (SC Bucuresti II), T. Udistroiu (SC Craiova), D. Vasile (SC Bucuresti I); Spain: J. J. López Ibor (CC), J. L. Carrasco (SC Madrid); Sweden: N. Lindefors (CC and SC Stockholm), G. Sedvall (CC), F. A. Wiesel (SC Uppsala); Switzerland: A. Riecher-Rössler (CC), U. Gschwandtner (SC Basel). 


\section{Acknowledgments}

EUFEST was funded by the European Group for Research in Schizophrenia (EGRIS) with grants from AstraZeneca, Pfizer and Sanofi-Aventis. The sponsors had no role in the study design, data collection, analysis or interpretation, writing of the report, or the decision to submit the paper for publication.

We thank Professor Dr H. Kuhl, Department of Gynecological Endocrinology, Zentrum für Frauenheilkunde und Geburtshilfe, University of Frankfurt, for useful advice and C. Pfister for help in preparing the manuscript. We also thank all participating patients and all contributors to the EUFEST Study Group.

\section{Declaration of Interest}

A.R.-R. has received unconditional grants from Eli Lilly, Janssen-Cilag, AstraZeneca, Bristol-Myers Squibb, Lundbeck and was advisory board member of Janssen-Cilag and Eli Lilly. J.K.R. has acted as a consultant or as a speaker for Adamed-Poland, BristolMyers Squibb, Eli Lilly, Janssen-Cilag, Lundbeck, Organon, Pfizer, Sanofi-Aventis, and Servier. R.S.K. has received grants, honoraria for education programs, or served as consultant for Astellas, AstraZeneca, BMS, Eli Lilly, Janssen-Cilag, Pfizer, Roche, and Sanofi-Aventis. W.W.F. receives research grants from Otsuka, Janssen, Reckitt Benckiser; has received consulting honoraria from Endo, Lundbeck, Roche, BMS, Otsuka, Janssen, Pfizer, Unitedbiosource, MedAvante, Sunovion, Merck; speaker honoraria from Lundbeck, Sunovion, Janssen, Eli Lilly, Otsuka, Roche; and owns MedAvante stocks.

\section{References}

Akhondzadeh S, Rezaei F, Larijani B, Nejatisafa AA, Kashani L, Abbasi SH (2006). Correlation between testosterone, gonadotropins and prolactin and severity of negative symptoms in male patients with chronic schizophrenia. Schizophrenia Research 84, 405-410.

Aston J, Rechsteiner E, Bull N, Borgwardt S, Gschwandtner U, Riecher-Rössler A (2010). Hyperprolactinaemia in early psychosis - not only due to antipsychotics. Progress in Neuro-Psychopharmacology and Biological Psychiatry 34, 1342-1344.

Büschlen J, Berger GE, Borgwardt SJ, Aston J, Gschwandtner U, Pflueger MO, Kuster P, Radü EW, Stieglitz R-D, Riecher-Rössler A (2010). Pituitary volume increase during emerging psychosis. Schizophrenia Research 125, 41-48.

Bushe C, Shaw M, Peveler RC (2008). A review of the association between antipsychotic use and hyperprolactinaemia. Journal of Psychopharmacology 22, 46-55.
Bushe CJ, Bradley AJ, Wildgust HJ, Hodgson RE (2009). Schizophrenia and breast cancer incidence: a systematic review of clinical studies. Schizophrenia Research 114, 6-16.

Chong RY, Uhart M, McCaul ME, Johnson E, Wand GS (2008). Whites have a more robust

hypothalamic-pituitary-adrenal axis response to a psychological stressor than blacks. Psychoneuroendocrinology 33, 246-254.

Dickson RA, Seeman MV, Corenblum B (2000). Hormonal side effects in women: typical versus atypical antipsychotic treatment. Journal of Clinical Psychiatry 61 (Suppl. 3), 10-15.

El Yazaji M, Battas O, Agoub M, Moussaoui D, Gutknecht C, Dalery J, d'Amato T, Saoud M (2002). Validity of the depressive dimension extracted from principal component analysis of the PANSS in drug-free patients with schizophrenia. Schizophrenia Research 56, 121-127.

Evans AM, Petersen JW, Sekhon GS, DeMars R (1989). Mapping of prolactin and tumor necrosis factor-beta genes on human chromosome $6 \mathrm{p}$ using lymphoblastoid cell deletion mutants. Somatic Cell and Molecular Genetics 15, 203-213.

Fitzgerald P, Dinan TG (2008). Prolactin and dopamine: what is the connection? A review article. Journal of Psychopharmacology 22, 12-19.

Fleischhacker WW, Keet IP, Kahn RS; EUFEST Steering Committee (2005). The European First Episode Schizophrenia Trial (EUFEST): rationale and design of the trial. Schizophrenia Research 78, 147-156.

Garcia-Rizo C, Fernandez-Egea E, Oliveira C, Justicia A, Parellada E, Bernardo M, Kirkpatrick B (2012). Prolactin concentrations in newly diagnosed, antipsychotic-naive patients with nonaffective psychosis. Schizophrenia Research 134, 16-19.

Garner B, Pariante CM, Wood SJ, Velakoulis D, Phillips L, Soulsby B, Brewer WJ, Smith DJ, Dazzan P, Berger GE, Yung AR, van den Buuse M, Murray R, McGorry PD, Pantelis C (2005). Pituitary volume predicts future transition to psychosis in individuals at ultra-high risk of developing psychosis. Biological Psychiatry 58, 417-423.

Guest PC, Schwarz E, Krishnamurthy D, Harris LW, Leweke FM, Rothermundt M, van Beveren NJ, Spain M, Barnes A, Steiner J, Rahmoune H, Bahn S (2011). Altered levels of circulating insulin and other neuroendocrine hormones associated with the onset of schizophrenia. Psychoneuroendocrinology 36, 1092-1096.

Guy W (1976). Clinical Global Impressions. In ECDEU Assessment Manual for Psychopharmacology - Revised, pp. 218-222 (DHEW publication number ADM 76-338). National Institute of Mental Health: Rockville, MD.

Haddad PM, Wieck A (2004). Antipsychotic-induced hyperprolactinaemia: mechanisms, clinical features and management. Drugs 64, 2291-2314.

Häfner H, Maurer K, Löffler W, Riecher-Rössler A (1993). The influence of age and sex on the onset and early course of schizophrenia. British Journal of Psychiatry 162, 80-86.

Howard L, Kirkwood G, Leese M (2007). Risk of hip fracture in patients with a history of schizophrenia. British Journal of Psychiatry 190, 129-134. 
Howes OD, Kapur S (2009). The dopamine hypothesis of schizophrenia: version III: - the final common pathway. Schizophrenia Bulletin 35, 549-562.

Hummer M, Malik P, Gasser RW, Hofer A, Kemmler G, Moncayo Naveda RC, Rettenbacher MA, Fleischhacker WW (2005). Osteoporosis in patients with schizophrenia. American Journal of Psychiatry 162, 162-167.

Kahn RS, Fleischhacker WW, Boter H, Davidson M, Vergouwe Y, Keet IP, Gheorghe MD, Rybakowski JK, Galderisi S, Libiger J, Hummer M, Dollfus S, Lopez-Ibor JJ, Hranov LG, Gaebel W, Peuskens J, Lindefors N, Riecher-Rössler A, Grobbee DE; EUFEST Study Group (2008). Effectiveness of antipsychotic drugs in first-episode schizophrenia and schizophreniform disorder: an open randomised clinical trial. Lancet 371, 1085-1097.

Kay SR, Fiszbein A, Opler LA (1987). The positive and negative syndrome scale (PANSS) for schizophrenia. Schizophrenia Bulletin 13, 261-276.

Kirschbaum C, Kudielka BM, Gaab J, Schommer NC, Hellhammer DH (1999). Impact of gender, menstrual cycle phase, and oral contraceptives on the activity of the hypothalamus-pituitary-adrenal axis. Psychosomatic Medicine 61, 154-162.

Klomp A, Koolschijn PC, Pol HE, Kahn RS, van Haren NE (2012). Hypothalamus and pituitary volume in schizophrenia: a structural MRI study. International Journal of Neuropsychopharmacology 15, 281-288.

Kraepelin E (1909-1915). Psychiatry, vols 1-4 [in German]. Barth: Leipzig.

Kretschmer E (1921). Körperbau und Charakter. Untersuchungen zum Konstitutionsproblem und zur Lehre von den Temperamenten [Physique and Character: An Investigation of the Nature of Constitution and of the Theory of Temperament]. 25th edn, 1967. Springer: Berlin, Heidelberg, New York.

Low WJ (2008). Neuroendocrinology. In Williams Textbook of Endocrinology (ed. H. M. Kronenberg, S. Melmed, K.

S. Polonsky and P. R. Larsen), pp. 85-295. W.B. Saunders Co.: Philadelphia, PA.

MacMaster FP, El-Sheikh R, Upadhyaya AR, Nutche J, Rosenberg DR, Keshavan M (2007). Effect of antipsychotics on pituitary gland volume in treatment-naive first-episode schizophrenia: a pilot study. Schizophrenia Research 92, 207-210.

Malik P, Kemmler G, Hummer M, Riecher-Rössler A, Kahn RS, Fleischhacker WW (2011). Sexual dysfunction in first-episode schizophrenia patients: results from European First Episode Schizophrenia Trial. Journal of Clinical Psychopharmacology 31, 274-280.

Miller KK (2004). Management of hyperprolactinemia in patients receiving antipsychotics. CNS Spectrums 9, 28-32.

Mizrahi R, Addington J, Rusjan PM, Suridjan I, Ng A, Boileau I, Pruessner JC, Remington G, Houle S, Wilson AA (2012). Increased stress-induced dopamine release in psychosis. Biological Psychiatry 71, 561-567.

O'Keane V, Meaney AM (2005). Antipsychotic drugs: a new risk factor for osteoporosis in young women with schizophrenia? Journal of Clinical Psychopharmacology 25, 26-31.
Pariante CM (2008). Pituitary volume in psychosis: the first review of the evidence. Journal of Psychopharmacology 22, 76-81.

Phillips LJ, McGorry PD, Garner B, Thompson KN, Pantelis C, Wood SJ, Berger G (2006). Stress, the hippocampus and the hypothalamic-pituitary-adrenal axis: implications for the development of psychotic disorders. Australian and New Zealand Journal of Psychiatry 40, 725-741.

Prabhakar VK, Davis JR (2008). Hyperprolactinaemia. Best Practice and Research: Clinical Obstetrics and Gynaecology 22, 341-353.

R Development Core Team (2011). R: A Language and Environment for Statistical Computing. R Foundation for Statistical Computing: Vienna, Austria.

Riecher-Rössler A, de Geyter C (2007). The forthcoming role of treatment with oestrogens in mental health. Swiss Medical Weekly 137, 565-572.

Riecher-Rössler A, Häfner H (1993). Schizophrenia and oestrogens - is there an association? European Archives of Psychiatry and Clinical Neuroscience 242, 323-328.

Riecher-Rössler A, Häfner H, Dütsch-Strobel A, Stumbaum M (1998). Gonadal function and its influence on psychopathology. Archives of Women's Mental Health 1, 15-26.

Riecher-Rössler A, Häfner H, Stumbaum M, Maurer K, Schmidt R (1994). Can estradiol modulate schizophrenic symptomatology? Schizophrenia Bulletin 20, 203-214.

Riecher-Rössler A, Kulkarni J (2011). Estrogens and gonadal function in schizophrenia and related psychoses. In Biological Basis of Sex Differences in Psychopharmacology (ed. J. C. Neill and J. Kulkarni), pp. 155-171. Springer: Heidelberg.

Riecher-Rössler A, Schmid C, Bleuer S, Birkhäuser M (2009). Antipsychotics and hyperpolactinaemia: pathophysiology, clinical relevance, diagnosis and therapy [in German]. Neuropsychiatry 23, 71-83.

Roig B, Virgos C, Franco N, Martorell L, Valero J, Costas J, Carracedo A, Labad A, Vilella E (2007). The discoidin domain receptor 1 as a novel susceptibility gene for schizophrenia. Molecular Psychiatry 12, 833-841.

Rybakowski JK, Dmitrzak-Weglarz M, Kapelski P, Hauser J (2011). Functional -1149 G/T polymorphism of the prolactin gene in schizophrenia. Neuropsychobiology 65, 4144.

Schwab SG, Mondabon S, Knapp M, Albus M, Hallmayer J, Borrmann-Hassenbach $M$, Trixler $M$, Gross $M$, Schulze TG, Rietschel M, Lerer B, Maier W, Wildenauer DB (2003). Association of tumor necrosis factor alpha gene-G308A polymorphism with schizophrenia. Schizophrenia Research 65, 19-25.

Segal M, Avital A, Rojas M, Hausvater N, Sandbank S, Liba D, Moguillansky L, Tal I, Weizman A (2004). Serum prolactin levels in unmedicated first-episode and recurrent schizophrenia patients: a possible marker for the disease's subtypes. Psychiatry Research 127, 227-235.

Stevens A, Ray D, Alansari A, Hajeer A, Thomson W, Donn R, Ollier WE, Worthington J, Davis JR (2001) 
Characterization of a prolactin gene polymorphism and its associations with systemic lupus erythematosus. Arthritis and Rheumatism 44, 2358-2366.

Tochigi M, Zhang X, Umekage T, Ohashi J, Kato C, Marui T, Otowa T, Hibino H, Otani T, Kohda K, Liu S, Kato N, Tokunaga K, Sasaki T (2004). Association of six polymorphisms of the NOTCH4 gene with schizophrenia in the Japanese population. American Journal of Medical Genetics. Part B, Neuropsychiatric Genetics 128B, 37-40.

Ungless MA, Argilli E, Bonci A (2010). Effects of stress and aversion on dopamine neurons: implications for addiction. Neuroscience and Biobehavioral Reviews 35, 151-156.

van Os J, Kenis G, Rutten BP (2010). The environment and schizophrenia. Nature 468, 203-212.

van Winkel R, Stefanis NC, Myin-Germeys I (2008).

Psychosocial stress and psychosis. A review of the neurobiological mechanisms and the evidence for gene-stress interaction. Schizophrenia Bulletin 34, 1095-1105.

Walter A, Riecher-Rössler A, Studerus E, Smieskova R, Tamagni C, Rapp C, Borgwardt S (2012). Pituitary gland volume in individuals with an at-risk mental state: a longitudinal MRI analysis. Schizophrenia Research 136 (Suppl. 1), S300.

Yasui-Furukori N, Saito M, Nakagami T, Sugawara N, Sato Y, Tsuchimine S, Furukori H, Kaneko S (2010). Gender-specific prolactin response to antipsychotic treatments with risperidone and olanzapine and its relationship to drug concentrations in patients with acutely exacerbated schizophrenia. Progress in Neuro-Psychopharmacology and Biological Psychiatry 34, 537-540. 